\title{
LICENCIATURA EM FÍSICA: FATORES INFLUENCIADORES QUANTO AO INGRESSO NESTA FORMAÇÃO ACADÊMICA
}

\author{
DEGREE IN PHYSICS: MOTIVATING FACTORS IN THE ENTRANCE IN THIS \\ ACADEMIC FORMATION
}

Ariel Gonçalves Marcelino ${ }^{1}$, João Bernardes Rocha Filho ${ }^{2}$, Luciano Denardin ${ }^{3}$

Recebido: janeiro/2019 Aprovado: outubro/2020

\begin{abstract}
Resumo: A constatação do baixo número de graduandos em licenciatura em física no Brasil motivou esta pesquisa, que se propôs a buscar respostas para a seguinte questão: quais são os fatores que influenciam o quadro em questão, que resulta em que apenas uma pequena parcela de universitários siga a formação docente em física? Foi adotada como metodologia de análise de dados a Análise Textual Discursiva (ATD) aplicada às respostas a um questionário contendo perguntas abertas e fechadas. Os quinze participantes são estudantes de graduação em licenciatura em física de uma universidade comunitária do Rio Grande do Sul, com ingresso nos anos de 2011 a 2018. Concluiu-se que os principais fatores são o interesse intrínseco dos participantes no que se refere aos conteúdos estudados nessa ciência, a aptidão cognitiva para aprendizagem dos mesmos conteúdos, e certa concepção de mundo relacionada à educação e à ciência.
\end{abstract}

Palavras-chave: licenciatura em física, fatores motivadores, ingresso acadêmico.

Abstract: The finding of the low number of undergraduate students in physics in Brazil motivated this research, which set out to seek answers to the following question: what are the factors that influence the situation in question, which results in only a small number of university students following teacher training in physics? The Discursive Text Analysis (DTA) was applied as the data analysis methodology applied to the answers to a questionnaire containing open and closed questions. The fifteen participants are undergraduate students in a degree in physics from a community university in Rio Grande do Sul, enrolled in the years 2011 to 2018. It was concluded that the main factors are the intrinsic interest of the participants with regard to the contents studied in this science, the cognitive aptitude for learning the same contents, and a certain conception of the world related to education and science.

Keywords: degree in physics, motivating factors, academic admission.

\section{Introdução e fundamentação teórica}

A licenciatura em física é a graduação com menos inscrições para vestibulares, com maior evasão durante o curso e com o menor percentual de conclusão. Como consequência, a física é

1 iD https://orcid.org/0000-0003-0375-6703-Graduado em Física Licenciatura pela Pontifícia Universidade Católica do Rio Grande do Sul (PUCRS). Professor celetista do Colégio Mesquita, Porto Alegre, Rio Grande do Sul, Brasil. Endereço completo para correspondência (Av. do Forte, 77, CEP: 91360-000-Porto Alegre-RS). E-mail: arielgmarcelino@gmail.com

2 iD https://orcid.org/0000-0002-5058-3107 - Doutor em Engenharia pela Universidade Federal de Santa Catarina (UFSC). Professor Titular da Pontifícia Universidade Católica do Rio Grande do Sul (PUCRS), Porto Alegre, Rio Grande do Sul, Brasil. Endereço completo para correspondência (Av. Ipiranga, 6681 - Prédio 32 - sala 707, CEP: 90619-900 - Porto Alegre -RS). E-mail: jbrfilho@pucrs.br

3 ID https://orcid.org/0000-0001-8839-2229 - Doutor em Educação em Ciências e Matemática pela Pontifícia Universidade Católica do Rio Grande do Sul (PUCRS). Professor Adjunto da Pontifícia Universidade Católica do Rio Grande do Sul (PUCRS), Porto Alegre, Rio Grande do Sul, Brasil. Endereço completo para correspondência (Av. Ipiranga, 6681 - Prédio 32 - sala 712, CEP: $90619-900$ - Porto Alegre - RS). E-mail: luciano.denardin@pucrs.br 
a disciplina do ensino médio com a menor quantidade de profissionais habilitados para lecionar, entre todas as demais (SANTOS, 2018).

Um dos fatores que contribuem para que poucos concluintes do ensino médio escolham a licenciatura em física como opção de inscrição no vestibular parece ter relação com o fato de que a maioria dos professores em serviço não atua como agente de motivação para o desenvolvimento do apreço dos alunos do ensino médio pela física, enquanto ciência experimental. Neste sentido, Pastorini (2013, p. 63), em uma pesquisa que envolveu centenas de estudantes do ensino médio, verificou que:

[...] os professores observados se mostraram, em geral, incapazes de expor a seus alunos uma física capaz de interessá-los, de forma que esses a estudam apenas o suficiente para passar para o ano seguinte, concluir a escola ou para concursos e vestibulares. Como os dados de outras pesquisas mostram que o gosto por ciências é elevado no ensino fundamental, possivelmente em algum momento ou ao longo do ensino médio os estudantes não conseguiram acompanhar o ritmo imposto pelo professor, ou sucumbiram às aulas tradicionais e sem aplicação. As atitudes negativas que encontramos nos professores observados mais que justificam o fato de que a física é a licenciatura menos procurada entre todas as formações que conduzem ao magistério do núcleo comum do ensino médio.

Segundo Penteado e Pereira (2007) existem insatisfações dos professores relacionadas ao lazer, valorização salarial, ambiente de trabalho, serviços de saúde e meios de transporte. Essas insatisfações evidenciam, naquilo que tange aos professores de física da rede pública estadual (PASTORINI, 2013), a redução de status social do professor. A isso se somam a remuneração insuficiente ao atendimento de suas necessidades e a falta de materiais e espaços específicos para experimentação, que acabam por afetar o desempenho profissional, com consequências diversas, dentre as quais a baixa procura por formações continuadas.

$O$ adoecimento docente também se configura como um mal que atinge grande parcela dos professores (SANTOS; BARROS, 2018). Os fatores que expõem os professores a essa desvalorização frequentemente trazem a consequência da perda da identidade profissional (GARCIA; BATISTA; SILVA, 2018), acarretando fadiga, redução de perspectivas e de prazer no ensino, e o consequente sofrimento psicossomático, tudo intimamente ligado à desvalorização econômica e ao crescente desprestígio do magistério (SANTOS, 2015).

Ainda nessa perspectiva, Rocha Filho (2015) afirma que a forma avaliativa do ensino transmissivo, que geralmente aponta o erro como uma falha que deve ser punida e, também, a desmotivação dos professores constituem-se em problemas que implicam aulas que não traduzem a natureza da ciência, seu caráter de constante evolução e sua essência experimental. Sem a alfabetização científica, que seria consequência de um ensino interdisciplinar e contextualizado (CARLOS, 2007), faltam interesse e curiosidade nos alunos e, consequentemente, a opção profissional pelas ciências, e especialmente pela física, fica prejudicada.

Diante da falta de interesse dos alunos do ensino médio a respeito da física, uma consequência natural é a escassez de professores de física. Este grupo profissional representa a 
menor quantidade de licenciados no Brasil dentre todas as licenciaturas que levam às componentes curriculares da base curricular atual do ensino médio, além de ser o curso que tem o maior grau de evasão (ARAUJO; VIANNA, 2011). E isso vem piorando em anos mais recentes, embora o problema fosse sensível já na primeira década do século XXI. Comparando a física com outras disciplinas da área das ciências exatas, o número de licenciados entre 2002 a 2010 mostra esse desequilíbrio: a física formou 14.247 pessoas, enquanto a biologia formou 126.448 pessoas. Já entre os formados apenas no ano de 2005, a física ficou com 1.199 pessoas, quanto a matemática formou 10.057 professores (ARAUJO, 2008).

A escassez de professores dessa componente curricular, em vez de se refletir em maior valorização da categoria, levou as escolas a adotarem a estratégia de confiar suas turmas a professores não formados em física, mas sim em outras disciplinas da área das ciências, especialmente da matemática, mas também da biologia, da química e até das humanidades (SILVA, 2010). Aliás, isso merece uma reflexão mais aprofundada, pois mostra como a lei da oferta e da procura funciona perfeitamente quando beneficia o capital e os donos dos meios de produção, mas não quando se refere ao trabalhador.

Como consequência dessa decisão empresarial das escolas, surge um risco mais elevado de que a ação docente desses professores não habilitados a lecionar física fique aquém do necessário, perdendo-se a perspectiva global, contextualizada e adequada à pós-modernidade, não somente no conteúdo em si, mas também quanto à metodologia de ensino, terminando por contribuir para a redução da curiosidade e do interesse científico (GARCIA; BATISTA; SILVA, 2018). Isso, por sua vez, pode distanciar os alunos da física e fazer com que eles não busquem essa formação inicial, instalando um ciclo perverso que acarreta uma queda constante da procura por cursos de licenciatura em física.

Outros países enfrentam essa questão de modos diversos. Alguns deles pagam bem a seus professores, o que incentiva as pessoas a considerarem a carreira no magistério. Uma pesquisa de 2019 da Organização para a Cooperação e Desenvolvimento Econômico (OCDE), que comparou o poder de compra da média salarial de professores de 48 países, mostrou que o Brasil é o último do ranking. O primeiro colocado nesta lista, a Dinamarca, paga cerca de quatro vezes mais que o Brasil (O TEMPO, 2019).

Apesar disso, alguns poucos estudantes percebem na profissão docente um caminho a seguir, e uma fração destes buscam a licenciatura em física. Logo, é interessante e útil conhecer os fatores intervenientes nessa opção, por isso se fez esta investigação, enunciando-se a seguinte questão de pesquisa: quais fatores positivos e negativos foram considerados na sua decisão de seguir a formação para se tornar um docente em física?

Para responder à questão de pesquisa, então, foram considerados muitos aspectos nas respostas dos participantes, como a verificação da possível relação entre a escolha profissional e aprendizagem escolar na disciplina de física, a avaliação de possíveis habilidades intrínsecas do estudante para aprendizagem dos conhecimentos que compõem esta disciplina, a identificação da licenciatura em física como ponte acadêmica para obter conhecimentos específicos, e a análise de como a escolha pela docência em física está relacionada com a 
importância de alguma descoberta ou influência de pessoas, como algum profissional dessa área, por exemplo.

\section{Procedimentos Metodológicos}

A pesquisa apresentada neste trabalho é de natureza qualitativa (BOGDAN; BIKLEN, 1994). Os participantes da pesquisa foram quinze estudantes da graduação em Licenciatura em física de uma universidade comunitária do Rio Grande do Sul, com ingresso nos anos de 2011 a 2018, e idades entre dezenove e vinte e oito anos. Em relação ao sexo biológico dos participantes, dez eram do sexo masculino e cinco do feminino. A escolha dessas pessoas, dentre todas as que estudam no curso, foi baseada unicamente na disponibilidade de tempo e facilidade de acesso às mesmas, contudo, destaca-se que havia participantes da pesquisa que estavam no começo, meio e fim do curso.

O instrumento de coleta de dados utilizado na pesquisa aqui descrita foi um questionário. $\mathrm{O}$ uso de questionário tem como vantagens o fato de os participantes da pesquisa poderem respondê-lo em qualquer local e instante que desejarem, viabiliza rapidamente uma profusão de dados e mantém o anonimato dos respondentes (GRAY, 2012). O questionário combinou perguntas abertas e fechadas, voltadas ao interesse da pesquisa (CHIZZOTTI, 2018). A elaboração das questões atentou para que algumas fossem abrangentes e abertas, no sentido de permitir aos participantes da pesquisa trazer elementos não previamente estabelecidos pelos pesquisadores, como ocorre nas questões 1,4 e 7 .

Optou-se por aplicar o questionário de modo a possibilitar aos participantes o tempo que quisessem para respondê-lo, a fim de obter manifestações mais refletidas, podendo fazê-lo em suas casas. $O$ tempo de devolução do questionário variou entre um dia e duas semanas. Abaixo, encontram-se, de acordo com a questão de pesquisa, as perguntas que constituem o questionário aplicado:

1) Como considera a qualidade de ensino da disciplina de física ao longo do seu ensino básico, a respeito dos professores, laboratórios e demais condições de ensino?

2) Houve conteúdos de física que você gostou mais ao estudá-los? Quais? Poderia escrever sobre por que razões você gostou mais desses conteúdos?

3) Compare sua dificuldade na aprendizagem em física em relação à dificuldade que enfrentou nas outras disciplinas que estudou ao longo de sua trajetória no ensino básico.

4) Ao concluir a licenciatura em física você pensa que estará pronto para lecionar no ensino básico e/ou seguir estudos de pós-graduação na linha de ensino/educação ou em outras linhas das ciências exatas ou humanas. Você já tem planos sobre isso? Quais seriam?

5) Em que medida você entende que a divulgação científica (filmes, documentários, biografias de cientistas, museus de ciências, livros e revistas de divulgação, etc.) contribuiu para sua escolha pela licenciatura em física? 
6) Em que medida você entende que a influência de familiares, amigos, conhecidos ou professores contribuiu para sua escolha pela licenciatura em física?

7) Qual/quais outros fatores influenciaram você a ingressar na licenciatura em física?

As respostas ao questionário foram expostas a uma Análise Textual Discursiva (ATD) (GALIAZZI; MORAES, 2011). Conforme os autores (p.11), esse método de análise "não pretende testar hipóteses para comprová-las ou refutá-las ao final da pesquisa, a intenção é a compreensão, reconstruir conhecimentos existentes sobre os temas investigados". Embora a ATD trabalhe com ênfase em respostas transcritas na íntegra, ela pode ser aplicada aos dados recolhidos a partir de qualquer instrumento para a coleta de informações.

A ATD é um método de análise constituído por três etapas. A primeira é denominada unitarização e consiste na fragmentação do material coletado em pequenos recortes denominados unidades de significado. No caso deste trabalho as unidades de significado são as respostas (ou trechos delas) dadas pelos participantes da pesquisa no questionário. A categorização configura a segunda etapa da ATD e caracteriza-se pelo agrupamento das unidades de significado que possuem semelhanças e congruências. A esses grupos de unidades de significado dá-se o nome de categoria. A elaboração de metatextos que "representam construções e interpretações pessoais do pesquisador, tendo sempre como referência uma fidelidade e respeito às informações obtidas com os sujeitos da pesquisa" caracteriza a terceira etapa da ATD, chamada de comunicação do "novo emergente" (GALIAZZI; MORAES, 2011, p. 116).

A etapa da desmontagem do corpus se efetivou após leitura completa e cuidadosa de todas as narrativas constantes nas respostas dos quinze participantes. A partir daí deu-se a desmontagem de cada uma das narrativas individuais, no sentido de unitarizá-las conforme cada um dos questionamentos. Então, as informações coletadas individualmente passaram a ser analisadas coletivamente, estabelecendo-se relações entre as respostas dos participantes, ou seja, categorizando-as, sem perder de vista a questão de pesquisa.

A partir das relações entre as unidades de significado emergiram seis categorias. A produção dos metatextos partiu da descrição de cada categoria estabelecida (em função das unidades que a compõem), passando por uma interpretação mais ampla da mesma por meio da articulação com referenciais teóricos até formar "argumentos aglutinadores" (GALIAZZI; MORAES, 2011, p.36).

\section{Resultados e Discussão}

A partir da análise das respostas ao questionário emergiram seis categorias que são apresentadas nas subseções abaixo.

CATEGORIA 1: A experimentação e a vivência como estudante 
Essa categoria versa sobre a vivência experimentada pelos participantes da pesquisa, enquanto alunos de ensino médio, como influência na escolha pela licenciatura em física como curso superior.

Em relação aos professores de física que os participantes da pesquisa tiveram no ensino médio, sete respondentes os classificaram como "bons" ou "legais"; três como "ótimos"; quatro sinalizaram elementos de frustração com o fazer docente de seus professores, apontando-os como "fracos" ou "medianos". Um dos participantes não respondeu a esta questão. Esses resultados são mostrados na Figura 1.

Figura 1 - Classificação qualitativa dos professores de física, segundo os participantes.

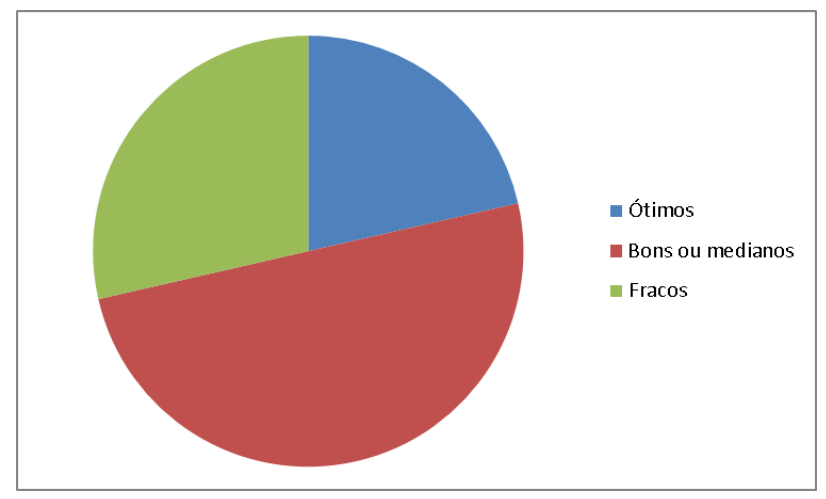

Fonte: o autor.

O gráfico mostrado na Figura 1 indica que relativamente poucos estudantes de licenciatura em física tiveram professores que julgam fracos. Isso sugere a importância de que bons professores de física sejam formados para o ensino básico.

Dentre os que classificaram os professores como "medianos", um deles destacou o fato de seu professor ser formado em matemática, o que dificultava a compreensão de conceitos da física. Esse aspecto está em consonância com o verificado em pesquisas anteriores, como a de Silva (2010) que constatou que muitos professores que lecionam a disciplina de física não têm formação na área. Com isso, esses professores podem sentir maior dificuldade ao tentarem contextualizar os conteúdos de física, por exemplo, o que, para Lunkes e Rocha Filho (2011) é um dos motivos da pequena procura pela licenciatura em física.

Alguns consideram "bons" ou "legais" seus professores, ainda que estes ministrem aulas convencionais, ou apenas expositivas-dialogadas. Nesse sentido, parece que um professor pode ser adjetivado como "legal", por exemplo, mais pelo seu gosto musical ou estilo de se vestir, do que pelas estratégias metodológicas que adota em sala de aula. Esse foi o caso de um participante de pesquisa que verbalizou que "meu professor de física, até que era legal, era roqueiro, fã de Beatles".

Um dos participantes da pesquisa afirmou ter tido "ótimos professores", apesar de considerar o ensino como sendo "fraco". O "ensino fraco" foi entendido pelo participante como resultado conjuntural de greves, falta de profissionais e precarização dos espaços físicos da escola. 
Quanto ao uso do laboratório de física, aquele participante que não respondeu quanto ao professor alegou que não cursou o ensino médio de forma regular, por isso não responderia as três primeiras questões do instrumento de coleta de dados. Incluindo a resposta desse participante, oito respondentes relataram que não tiveram aulas de física com experimentos de laboratório, enquanto sete participantes tiveram algum acesso a experimentos ou laboratório, embora com grandes restrições, expostas a seguir.

Borges e Rocha (2012) apontam que a falta de realização de atividades experimentais em aulas de física da educação básica se dá pelo fato de que muitas escolas não têm esse espaço físico. Os autores complementam que a diminuta carga horária da disciplina de física, somada à demanda cognitiva, física e temporal que o planejamento de uma aula prática exige contribui para a escassez desse tipo de atividade. Em geral, o professor trabalha em mais de uma escola, tendo uma carga horária elevada (OLIVEIRA; MANZANO, 2015). A realização de atividades experimentais requer uma montagem prévia dos dispositivos, exigindo uma disponibilidade de tempo que possivelmente o professor não tem. Ademais, os laboratórios escolares dificilmente comportam muitos estudantes, fazendo com que a turma tenha que ser dividida, fator que dificulta ainda mais a realização das atividades experimentais, pois os estudantes têm que ser separados e colocados em dois espaços físicos diferentes (sala de aula e laboratório) e o professor não conseguirá atendê-los de forma simultânea.

Em relação à experimentação, Wesendonk e Terrazzan (2020) verificaram que a formação inicial em física tem influência direta na frequência com que os professores propõem atividades com este viés. Borges e Rocha (2012) constataram também que alguns professores não se sentem aptos a realizarem atividades experimentais. Eles sugerem que isso pode ocorrer por ser comum às escolas terem docentes que não são formados em física lecionando essa disciplina, mas também alertam que "mesmo os devidamente formados em física, não se sentem confortáveis quando o assunto é aula no laboratório" (p. 163).

Um dos participantes da pesquisa afirmou que o uso do laboratório se resumiu à realização de "exercícios matemáticos". A ênfase na memorização e na resolução de exercícios algébricos que preparem os alunos para os vestibulares e ENEM são predominantes no ensino de física (ROSA; ROSA, 2005; BORGES; ROCHA, 2012). O fato de o participante declarar a resolução de exercícios nas aulas experimentais pode ser entendido como uma subutilização do laboratório escolar. Para Lunkes e Rocha Filho (2011), a ênfase matemática dada na disciplina de física também é um dos fatores que distanciam os concluintes do ensino médio a optarem pela carreira docente em física.

Dois participantes da pesquisa relataram ter "aulas práticas no laboratório de física", mas que eram em pouca quantidade. Como curiosidade, para o fechamento da amostra, pode-se elencar a fala de um dos licenciandos: "estudei em uma escola pública. Havia um laboratório de ciências muito completo, porém ele foi substituído por vários computadores não utilizáveis".

Evidencia-se, por meio destas colocações, que a categoria $A$ experimentação e a vivência como estudante contém elementos que remetem à qualidade de ensino. Aspectos do texto não apenas explícitos, mas também subjacentes, sugerem que é possível avaliar que são 
confirmados os conhecimentos já levantados em outros trabalhos e estudos. Autores como Brock e Rocha Filho (2011) já haviam identificado a baixa ou insuficiente qualidade do ensino dos conteúdos da disciplina de física ao longo do ensino médio, assim como a diminuta realização de atividades experimentais.

Apesar da qualidade de ensino não ter sido boa para a maioria dos entrevistados, o fato deles classificarem majoritariamente seus professores de física como bons e/ou ótimos pode ser um indicativo de que, no que se refere ao espaço escolar, é a pessoa do professor que mais influencia a favor da escolha pelo curso de licenciatura em física, o que corrobora Lunkes e Rocha Filho (2011).

\section{CATEGORIA 2: Interesse intrínseco e aptidão cognitiva para aprendizagem dos conteúdos da física}

Em relação a terem gosto pelos conteúdos abordados durante as aulas de física, dez participantes da pesquisa responderam que "sim". Três deles demonstraram-se "indiferentes", e um disse recordar-se pouco de qualquer conteúdo trabalhado. Um dos participantes deixou esta questão em aberto.

A maioria dos participantes revelou "gosto", afinidade ou interesse pelos conteúdos abordados na disciplina de física, independentemente da qualidade de ensino que tiveram. Além disso, um dos participantes relatou que sua opção pela física se deu pelo fato de querer "entender o universo", ou seja, parece que a curiosidade intrínseca à área influencia a escolha da carreira profissional.

Quanto à terceira pergunta do questionário, os participantes foram solicitados a compararem suas dificuldades de aprendizagem em física com relação às das outras disciplinas. Sobre esse aspecto, um dos participantes não respondeu à questão, um deles escreveu que acredita que em física teve mais dificuldades do que em qualquer outra disciplina cursada no ensino médio, três participantes relataram ter mais dificuldade em física do que em algumas disciplinas, e dez participantes disseram que tinham mais facilidade na aprendizagem na disciplina de física do que em outras disciplinas, como mostrado na Figura 2.

Figura 2 - Grau comparativo de dificuldade de aprender física em relação às outras disciplinas

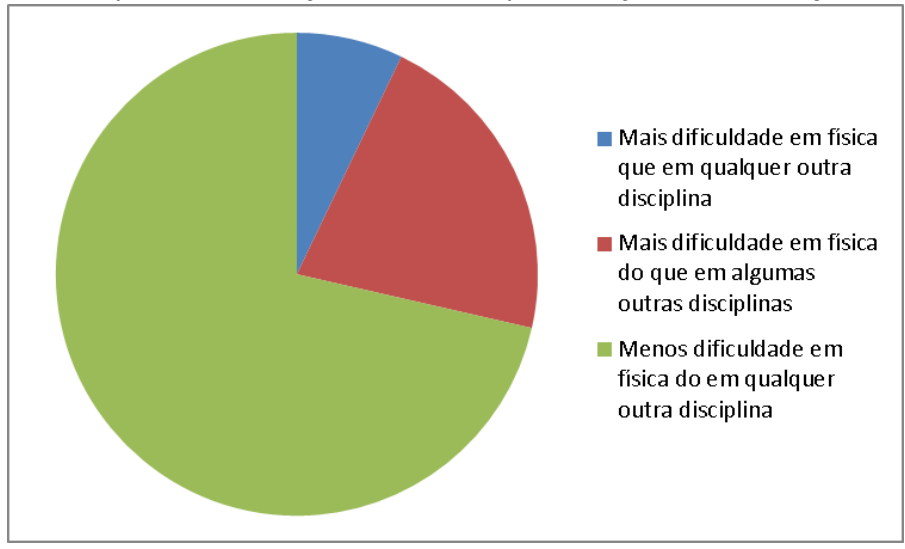

Fonte: o autor

O gráfico mostrado na Figura 2 indica que uma grande parcela dos participantes tinha certa facilidade de aprender física. Seria preciso fazer um estudo mais aprofundado para que se 
possa afirmar isso, mas é crível que o fato se deva a características intrínsecas da pessoa, provavelmente relacionadas ao raciocínio matemático, à curiosidade sobre o funcionamento da natureza, etc.

Assim, se identifica objetivamente o que poderia constituir-se apenas em senso comum. A evidência do interesse intrínseco às questões tratadas na física e a facilidade com essa disciplina se desenvolve constitui um elemento aparentemente importante na escolha pelo curso superior em física.

\section{CATEGORIA 3: Desejo de mudança por meio da educação e da ciência}

Quatro participantes da pesquisa apontaram o desejo de mudança, no sentido de construir uma educação melhor, como um dos motivos levados em consideração na escolha pela licenciatura em física. Entre esses quatro, dois demonstraram resiliência diante das dificuldades, e um afirmou que:

Quando comecei a me interessar em física eu não queria a licenciatura em física porque achava uma carreira muito pesada e conturbada [...] No final de 2016 eu me toquei que era um preconceito meu e que isso não deveria atrapalhar o meu sonho de formar pessoas (...) mas uma coisa é certa, ninguém escolhe licenciatura porque quer conforto, estabilidade ou dinheiro.

A fala desse participante mostra que o papel de contribuir para a formação de cidadãos críticos prevalece, mesmo com todas as dificuldades inerentes à carreira docente. Lunkes e Rocha Filho (2011) destacam que a baixa valorização social do magistério é uma das razões da pequena procura pela licenciatura em física. A ressalva presente no recorte discursivo do participante da pesquisa vai ao encontro da ideia preconizada pelos autores.

Um dos participantes afirmou que a licenciatura lhe permite compartilhar seu "amor" pela física; dois dos participantes relataram que apenas perceberam sua vontade de lecionar já na graduação. Um dos participantes frequentava o curso de engenharia, e comenta: "Na verdade, o que me fez optar pela licenciatura foi perceber que eu frequentemente me imaginava ensinando os conteúdos de física para alunos de ensino médio". Um mencionou a busca pelo conhecimento mais profundo da realidade e seu papel na sociedade; Outra manifestou a vontade de ser "formadora de opinião", ou o desejo de influenciar de modo positivo os alunos, assim como seus professores o fizeram. Essa participante também declarou que: "se eu puder fazer isso tudo por um único aluno, sei que terei cumprido o meu papel, porém a melhor parte é que poderei fazer com muitas vidas".

Apesar de todas as dificuldades relatadas, mudar o mundo, formar opinião, influenciar vidas, ou seja, fazer a diferença do ponto de vista profissional e humano na sociedade mostramse elementos motivadores para o ingresso na licenciatura em física, conforme os participantes, apesar da desvalorização dos professores (PENTEADO; PEREIRA, 2007; SANTOS, 2015).

Embora diante da singularidade e complexidade dos relatos para esta questão, é perceptível, após muitas leituras sensíveis das respostas completas dos quinze participantes, 
que o "desejo de mudança por meio da educação e da ciência" é um fator que pesa na escolha pela licenciatura em física.

\section{CATEGORIA 4: 0 papel da divulgação científica}

Quanto à possibilidade de a divulgação científica ter influenciado os acadêmicos, verificou-se que sete participantes responderam que de alguma forma sim, houve contribuição. Os outros oito respondentes mencionaram que não, sendo que as palavras de um entre esses oito foram "acredito que não tenha influenciado apesar de depois de entrar na faculdade ter me interessado bastante pelo assunto".

O fato dos participantes terem verbalizado que o gosto intrínseco à física influencia na decisão pela escolha do curso superior, pode ser relacionado com alguns deles assistirem documentários, podcasts e outros recursos midiáticos relacionados à ciência. Somado a isso, praticamente metade dos participantes da pesquisa valorizaram a divulgação científica como fator que contribui para a escolha pela licenciatura em física.

\section{CATEGORIA 5: Influência de pessoas próximas}

A influência de algum familiar ou de pessoas próximas para escolha da Licenciatura em física foi alvo da investigação por meio da questão número seis do questionário. Oito participantes declararam que não optaram pela licenciatura em física por influência de familiares ou pessoas próximas, mas sete deles informaram que sim, houve influência por parte de familiares ou pessoas próximas, como amigos e professores, por exemplo.

Importante ressaltar que no grupo dos oito estudantes que afirmaram não terem sido influenciados, dois deles reportaram que a família recebeu de forma negativa a escolha do curso de graduação. Neste sentido, os familiares agiram no sentido de fazer com que o participante desistisse desse curso de graduação. Como exemplo, a fala de um dos respondentes: "não tive proximidade com ninguém que me influenciasse a buscar a licenciatura. Ao contrário, comentários para que eu buscasse uma carreira 'boa', com bom salário [...]". Esse excerto mostra como a desvalorização do professor, detectada por Penteado e Pereira (2007) e Santos (2015) está presente na sociedade, fazendo com que os familiares sugiram que o participante da pesquisa repensasse sua escolha profissional por conta de salário e condições de trabalho, desconsiderando a vontade dele em seguir por essa carreira acadêmica.

O fato dos relatos dos quinze participantes do estudo se dividirem em partes mais ou menos iguais sobre sofrerem, ou não, influência de familiares e/ou pessoas próximas para a escolha da licenciatura em física sugere que esse é um fator relativamente importante, como já verificado em estudos anteriores (ALMEIDA; MELO-SILVA, 2011). Nesse sentido, os professores de física assumem um papel relevante, pois podem ser indutores da opção profissional em licenciatura em física em relação àqueles estudantes que têm essa predisposição, mas ainda não a identificaram.

CATEGORIA 6: Interesse dos participantes em seguirem a carreira docente 
Com relação ao interesse dos participantes em seguirem a carreira docente acadêmica, na área ou em outras áreas, quatro dos respondentes informaram que, além da licenciatura, não têm planos de futuros estudos. Três outros almejam cursar outra graduação, em outra área do conhecimento que não seja na educação. Três responderam que após a licenciatura vislumbram se dedicar a um curso de pós-graduação em outra área da física. Três informaram que, além da licenciatura, desejam dar continuidade aos seus estudos com mestrado na área da Educação. Os dois últimos, que podem ser agrupados, responderam que "pretendo concomitantemente seguir estudos de pós-graduação em educação, e também não excluo a possibilidade de seguir os estudos em outras linhas de formação, como a física médica, etc." e que "quero assim que me formar começar um mestrado, doutorado, e futuramente fazer outras graduações, matemática ou química, e psicologia (...)”. Esses dados são mostrados graficamente na Figura 3.

Figura 3 - Planejamentos sobre formação continuada

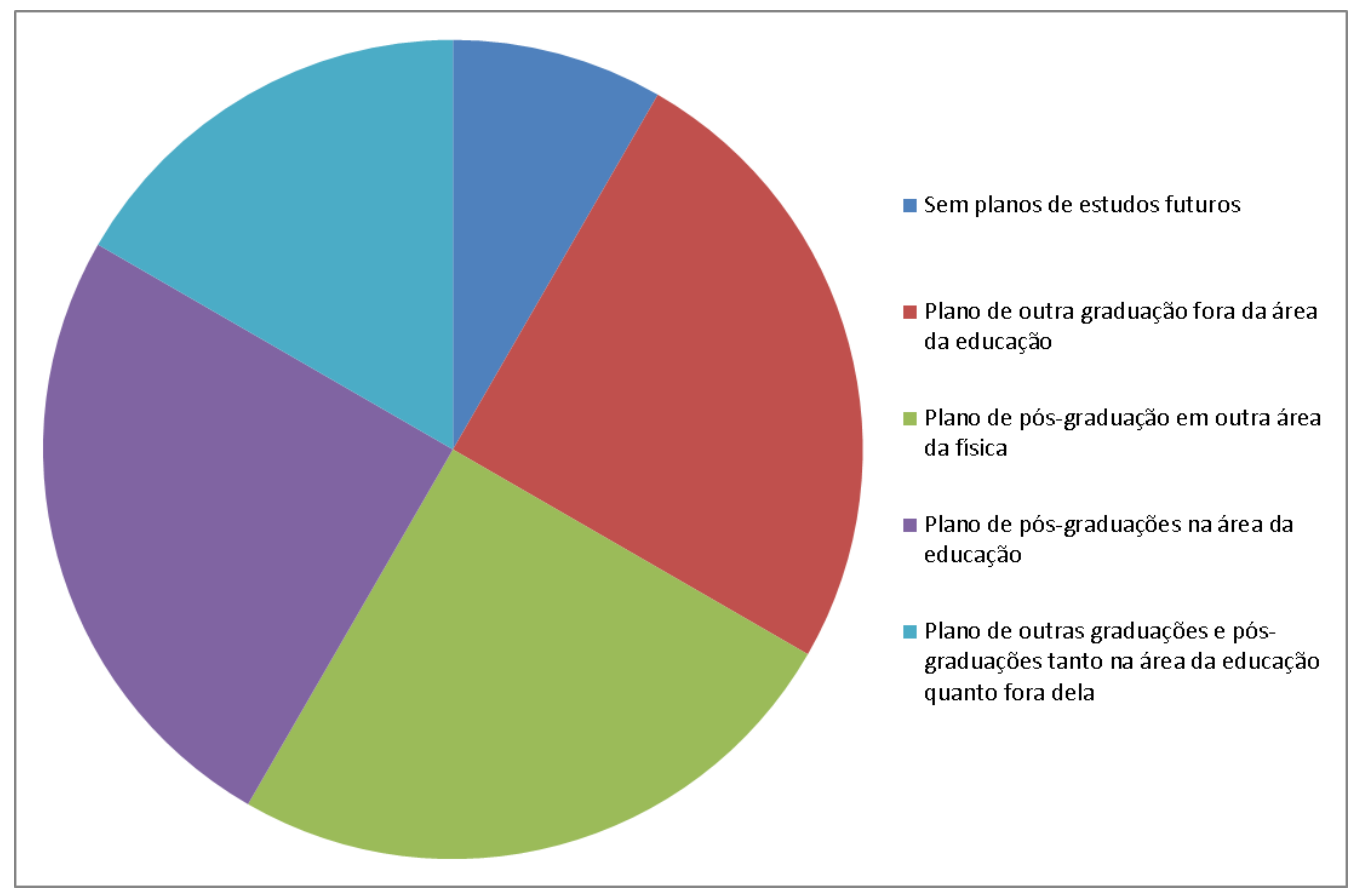

Fonte: o autor

O gráfico mostrado na Figura 3 indica uma grande dispersão de planejamentos quanto a estudos futuros, entre os participantes. $O$ que chama a atenção é a pequena parcela que não tem esses planos. Isso, obviamente, é bom, na medida em que os avanços contínuos no conhecimento implicam que o professor assuma uma atitude de formação continuada permanente.

\section{Considerações Finais}

Este trabalho procurou identificar, especialmente, quais fatores levaram um grupo de estudantes que ingressaram entre os anos de 2011 e 2018 em uma universidade comunitária do Rio Grande do Sul a optarem pela graduação em licenciatura em física. 
Considerou-se pertinente, conforme as informações, interpretações e reflexões resultantes desta investigação, e a totalidade das colocações dos participantes no desenvolvimento de suas respostas, que os principais elementos motivadores para o ingresso nessa formação acadêmica foram dois:

a) O interesse intrínseco dos participantes no que se refere aos conteúdos da disciplina de física;

b) a aptidão cognitiva para aprendizagem dos conteúdos ministrados neste componente curricular.

Ambos se imbricam nos depoimentos coletados por intermédio da pergunta número sete, referente a outros fatores que levaram à graduação em licenciatura em física. Tais influências, porém, se associam a um terceiro elemento motivador:

c) concepção de mundo diferenciada por parte dos respondentes, relacionada à educação e ciência.

No entanto, não se podem desconsiderar os demais fatores que emergiram dos dados, isso porque é necessário que, em uma investigação científica, as sutilezas das colocações dos participantes sejam levadas em conta com sensibilidade. Em especial, pode-se citar aquele que se refere à influência de pessoas próximas como sendo determinante para escolha da licenciatura em física.

Por meio da questão número seis, por exemplo, observou-se que certo percentual significativo de participantes mencionou o próprio professor como agente decisivo na opção pela licenciatura em física. Isso encontra respaldo em Pastorini (2013), embora essa autora conclua que existe uma parcela de professores que atua de forma a incentivar os estudantes a estudar licenciatura em física no nível superior, há outra parcela, muitíssimo maior em número, que acaba por distanciar seus alunos do ingresso na licenciatura em física. Em contrapartida, ainda com base nas respostas obtidas nesta questão, pôde-se constatar, de maneira empírica, como a desvalorização dos professores em nossa sociedade (PENTEADO; PEREIRA, 2007) implica negativamente na escolha dos licenciandos em física, os desmotivando e fazendo que até mesmo familiares ajam como opositores quanto a essa decisão.

Após essa pesquisa foi formado um novo questionamento, talvez como problema a ser abordado por meio de uma futura pesquisa: quais seriam as diferenças desses estudantes em relação aos demais, mediante a análise de suas histórias de vida? Essa pesquisa, porém, com um caráter muito mais centrado na intimidade do mundo psicológico dos participantes, exigirá a redução do número de participantes e o mergulho nas profundezas da psique humana. Futuramente, esta compreensão poderia promover uma intervenção na área educacional, na perspectiva de que um número maior de estudantes do ensino médio viesse a se interessar pela formação acadêmica na graduação em licenciatura em física.

\section{Referências}

ALMEIDA, F. H.; MELO-SILVA, L. L. Influência dos pais no processo de escolha profissional dos filhos: uma revisão da literatura. Psico-USF, v. 16, n. 1, p. 75-85, 2011. 
ARAUJO, R. S.; VIANNA, D. M. Discussões sobre a remuneração dos professores de física na educação básica. Ciência em Tela, v. 1, n. 2, p. 1-9, 2008. Disponível em: http://www.cienciaemtela.nutes.ufrj.br/artigos/0208araujo.pdf. Acesso em: 08 dez. 2020.

BOGDAN, R. C.; BIKLEN, S. K. Investigação qualitativa em educação: uma introdução à teoria e aos métodos. Porto: Porto Editora, 1994, 335p.

BORGES, J. C.; ROCHA, I. R. Análise e reflexões sobre a formação docente e o ensino de física experimental no Rio Grande do Norte. HOLOS, v. 3, p. 159-171, 2012.

BROCK, C.; ROCHA FILHO, J. B. Algumas origens da rejeição pela carreira profissional no magistério em física. Caderno Brasileiro de Ensino de Física, v. 28, n. 2, p. 356-372, 2011. Disponível em: https://dialnet.unirioja.es/servlet/articulo?codigo=5165364. Acesso em $08 \mathrm{dez}$. 2020.

CARLOS, J. G. Interdisciplinaridade no Ensino Médio: desafios e potencialidades. (2007). (Dissertação de Mestrado). Universidade de Brasília. Programa de Pós-graduação em Ensino de Ciências na UnB. 2007. Disponível em: http://repositorio.unb.br/handle/10482/2961. Acesso em 08 dez. 2020.

CHIZZOTTI, A. Pesquisa em ciências humanas e sociais. São Paulo: Cortez Editora, 2018.

GALIAZZI, M. do C.; MORAES, R. Análise textual discursiva. Ijuí: Editora Unijuí, 2011.

GARCIA, M. F.; BATISTA, M. C. S.; SILVA, D. A escolha da carreira docente em física: tensões e desafios. Caderno Brasileiro de Ensino de física, v. 35, n. 1, p. 42-63, 2018. Disponível em: https://periodicos.ufsc.br/index.php/fisica/article/view/2175-7941.2018v35n1p42. Acesso em 08 dez. 2020.

GRAY, D. E. Pesquisa no Mundo Real: Série Métodos de Pesquisa, 2. ed. Porto Alegre: Penso, 2012. 488p.

LUNKES, M. J.; ROCHA FILHO, J. B. A baixa procura pela licenciatura em física, com base em depoimentos de estudantes do ensino médio público do Oeste Catarinense. Ciência \& Educação, v.17, n.1, p. 21-34, 2011.

OLIVEIRA, L. D.; MANZANO, R. C. Uma aproximação ao sistema educativo e ao ensino (de ciencias) no Brasil. Boletín das ciencias, v. 28, n. 80, p. 79-90, 2015.

O TEMPO. Brasil é último em ranking de salários de professores. Portal de Educação, Rio de Janeiro, publicado em 21 jun. 2019. Disponível em: https://www.otempo.com.br/brasil/brasile-ultimo-em-ranking-de-salarios-de-professores-1.2199090. Acesso em 08 dez. 2020.

PASTORINI, R. C. Investigando as atitudes dos docentes do ensino básico que vêm influenciando negativamente a imagem da disciplina de física. (2013). (Dissertação de Mestrado). Programa de Pós-Graduação em Educação em Ciências e Matemática. Pontifícia Universidade Católica do Rio Grande do Sul. 2013. Disponível em: http://repositorio.pucrs.br/dspace/bitstream/10923/5623/1/000453311-Texto\%2BCompleto0.pdf. Acesso em 08 dez. 2020.

PENTEADO, R. Z.; PEREIRA, I. M. T. B. Qualidade de vida e saúde vocal de professores. Revista de Saúde Pública, v. 41, n. 2, p. 236-243, 2007. Disponível em: https://www.scielo.br/scielo.php?script=sci_abstract\&pid=S0034$89102007000200010 \& \operatorname{lng}=e n \& n r m=i s o \&$ tIng=pt. Acesso em 08 dez. 2020.

PENTEADO, R. Z. Autonomia do professor: uma perspectiva interdisciplinar para a cultura do cuidado docente. Campinas, Educação Temática Digital, v. 20, n. 1, p. 234, 2018. Disponível em: http://search.proquest.com/openview/1cc871f7fd0380d356b68dd415b7e486/1?pqorigsite=gscholar\&cbl=2029534. Acesso em: 08 dez. 2020. 
ROCHA FILHO, J. B. Física no Ensino Médio: Falhas e Soluções. Porto Alegre: EDIPUCRS, 2015.

ROSA, C. W.; ROSA, Á. B. Ensino de física: objetivos e imposições no ensino médio. Revista Electrónica de Enseñanza de las Ciencias, v. 4, n. 1, 2005.

SANTOS, F. W. C.; BARROS, L. M. As variáveis do adoecimento psíquico em docentes da saúde: Um estudo de caso. Semana de Pesquisa da Universidade Tiradentes-SEMPESq, n. 18, 2016. Disponível em: https://eventos.set.edu.br/index.php/sempesq/article/view/4332. Acesso em 08 dez. 2020.

SANTOS, G. M. O. Um olhar sobre a política de formação de professores de física no Brasil. (2018). 150 f. Dissertação (Mestrado em Ensino de Ciências e Matemática) - Universidade Federal de Sergipe, São Cristóvão, SE, 2018. Disponível em: http://ri.ufs.br/jspui/handle/riufs/7791. Acesso em 08 dez. 2020.

SANTOS, W. A. Uma reflexão necessária sobre a profissão docente no Brasil, a partir dos cinco tipos de desvalorização do professor. Sapere Aude-Revista de Filosofia, v. 6, n. 11, p. 349-358, 2015. Disponível em: http://periodicos.pucminas.br/index.php/SapereAude/article/view/9764. Acesso em 08 dez. 2020.

SILVA, B. V. C. A natureza da ciência pelos alunos do ensino médio: um estudo exploratório. Latin-American Journal of Physics Education, v. 4, n. 3, p. 620-627, 2010. Disponível em: https://dialnet.unirioja.es/servlet/articulo?codigo=3696940. Acesso em: 09 dez. 2020.

WESENDONK, F. S.; TERRAZZAN, E. A. Condições acadêmico-profissionais para a utilização de experimentações por professores de física do ensino médio. Ensino de Ciências e Tecnologia em Revista - ENCITEC, v. 10, n. 1, p. 39-55, 2020. 